DOI: $10.33947 / 2316-7394-v 7 n 1-3523$

\title{
DESENVOLVIMENTO DO SOFTWARE GERADOR DE EDITAIS PARA GANHO DE QUALIDADE E TEMPO NO PROCESSO DE LICITAÇÕES DE ÓRGÃOS PUBLICOS: ESTUDO DE CASO NA FUNDAÇÃO FLORESTAL
}

\section{DEVELOPMENT OF EDICTS GENERATOR SOFTWARE FOR QUALITY AND TIME GAIN IN THE PROCESS OF PUBLIC ORGANIC BIDDING: CASE STUDY IN THE FOREST FOUNDATION}

\author{
Matheus de Carvalho Dorth ${ }^{1}$
}

RESUMO: Os procedimentos que são feitos para a criação de um edital trouxeram à tona um problema de perda de tempo devido a tantas correções que são feitas de diferentes setores, trazendo uma realidade para qual necessitam de um método mais ágil. Esse artigo tem como objetivo estudar o desenvolvimento de um software para gerar editais pré-moldados que podem contribuir nos processos na Fundação Florestal.

PALAVRAS-CHAVE: Fundação Florestal. Gerador. Processos. Editais.

ABSTRACT: The procedures that are done to create an edictal carry a time problem due to series corrections that are made from different levels, bringing a reality to the requirements of a more agile method. This article aims to study the development of software to generate pre-edited editions and can be applied in the Forest Foundation processes.

KEYWORDS: Forest Foundation. Generator. Processes. Edicts.

Graduando em Ciências da Computação - Universidade UNIVERITAS/UNG. matheus_dorth@hotmail.com 


\section{INTRODUÇÃO}

Com o aumento de unidade de conservações e novos eventos nas unidades a demanda de compras de materiais, contratos de manutenção, contratação de mão de obra etc, tem gerado uma grande quantidade de novos editais no qual o mesmo precisa muita atenção para que no final seja cumprido o que foi licitado.

De acordo com o artigo 22 da Lei 8.666/93 são modalidades de licitação: Concorrência, Tomada de Preços, Convite, Concurso, Leilão. Nesse estudo de caso iremos discutir sobre a modalidade de licitação pregão, na forma eletrônica, instituída pela Lei $10.520 / 2002$, na qual foi regulamentada pelo Decreto $5.450 / 2003$, que se destina à aquisição de bens e serviços comuns. Os procedimentos para um Pregão Eletrônico, como modalidade de licitação do tipo menor preço, realizar-se-á quando a disputa pelo fornecimento de bens ou serviços comuns for feita à distância em sessão púbica, por meios de sistema que promova a comunicação pela internet. Consideram-se bens e serviços comuns, aqueles cujos padrões de desempenho e qualidade possam ser objetivamente definidos pelo edital, por meio de especificações usuais do mercado. Para o julgamento das propostas, serão fixados critérios objetivos que permitam aferir o menor preço, devendo ser considerados os prazos para a execução do contrato e do fornecimento, as especificações técnicas, os parâmetros mínimos de desempenho e de qualidade e as demais condições definidas no edital. O sistema para o pregão eletrônico será dotado de recursos de criptografia e de autenticação que garantam condições de segurança em todas as etapas do certame.

A Implantação do software nas estruturas do Governo de São Paulo, irá ter uma melhora de qualidade, redução de tempo, automatização do tramite entre setores na criação do edital, evitando que vários usuários do mesmo e de outros setores façam modificações atrasando e perdendo o foco do edital em questão, focando apenas em usuários chave com experiência para que o que está sendo licitado seja cumprido.

Não existe um gerador para editais, a proposta é apresentar um modelo para um futuro desenvolvimento para que seja aplicado em todo o método estrutural do Governo de São Paulo que é dividido em: Secretárias, Empresas, Autarquias, Fundações, Poder Público e Prefeituras Paulistas.

Esse artigo tem como objetivo estudar um método gerador de editais para que cada setor que vá desenvolver, crie, edite e avalie até o final do processo para melhor qualidade e redução de tempo.

\section{MATERIAIS E MÉTODOS}

Licitação é o procedimento administrativo mediante o qual a Administração Pública seleciona a proposta mais vantajosa para o contrato de seu interesse. (MEIRELLES, Hely Lopes, 2009). Tem como característica edital indicar ato pelo qual se publica pela imprensa, ou nos lugares públicos, certa notícia, fato ou ordenança que deve ser divulgada para conhecimento das pessoas nele mencionadas e de outras tantas que possam ter interesse no assunto. Um edital pode ser utilizado para aquisição de equipamentos, serviços, investimento, contratação de mão de obra, para exemplificar, qualquer órgão público que vá fazer uma aquisição de novos equipamentos para a área de informática precisa que seja feito um edital especificando todas as partes técnicas do equipamento que será comprado.

A linguagem JAVA como qualquer linguagem de programação, tem sua própria estrutura, regras de sintaxe e paradigma de programação. O paradigma de programação da linguagem Java baseia-se no conceito de OOP (Objetct Oriented Programming), que os recursos da linguagem suportam. A linguagem Java deriva da linguagem $C$, portanto suas regras de sintaxe assemelham-se às regras de $\mathrm{C}$. Por exemplo, os blocos de códigos são modularizados em métodos e delimitados por chaves ( $\{$ e $\}$ ) e variáveis são declaradas antes que sejam usadas. Estruturalmente, a linguagem Java começa com pacotes. Um pacote é o mecanismo de namespace da linguagem Java. Dentro dos pacotes estão as classes e dentro das classes estão métodos, variáveis, constantes e mais.

O BPM-Business Process Management (BPM) Gerenciamento de Processos de Negócio representa uma nova forma de visualizar as operações de negócio que vai além das estruturas funcionais tradicionais. Essa visão compreende todo o trabalho executado para entregar o produto ou serviço do processo, 
independentemente de quais áreas funcionais ou localizações estejam envolvidas. Começa em um nível mais alto do que o nível que realmente executa o trabalho e, então, subdivide-se em subprocessos que devem ser realizados por uma ou mais atividades (fluxos de trabalho) dentro de funções de negócio (áreas funcionais). As atividades, por sua vez, podem ser decompostas em tarefas e, adiante, em cenários de realização da tarefa e respectivos passos.

Bolsa Eletrônica de Compras - Governo do Estado de São Paulo. O Governo do Estado de São Paulo, lançou a Bolsa Eletrônica de Compras. Trata-se de um sistema informatizado para apuração do melhor preço de materiais e serviços adquiridos pelo setor público, cujas compras são realizadas através de pregões eletrônicos na internet.

Ferramenta MACRO MS-WORD. No Word, você pode automatizar tarefas usadas com frequência criando e executando macros. Um macro é uma série de comandos e instruções que você agrupa como um único comando para realizar uma tarefa automaticamente.

O MySQL foi originalmente desenvolvido pela empresa sueca TCX, que necessitava de um servidor de banco de dados que operasse com grandes escalas de dados rapidamente sem exigir caríssimas plataformas de hardware.

O Servidor MySQL foi desenvolvido originalmente para lidar com bancos de dados muito grandes de maneira muito mais rápida que as soluções existentes, e tem sido usado em ambientes de produção de alta demanda por vários anos de maneira bem-sucedida. Apesar de estar em constante desenvolvimento, o Servidor MySQL oferece hoje um rico e proveitoso conjunto de funções. A conectividade, velocidade, e segurança fazem com que o MySQL seja altamente adaptável para acessar bancos de dados na Internet. MySQL é um Sistema de Gerenciamento de Bancos de Dados relacional. Um banco de dados relacional armazena dados em tabelas separadas em vez de colocar todos os dados em um só local. Isso proporciona velocidade e flexibilidade. SQL é a linguagem padrão mais comum usada para acessar bancos de dados e é definida pelo Padrão ANSI/ISO SQL. (O padrão SQL vem evoluindo desde 1986 e existem diversas versões disponibilizadas).

O Termo de Referência - TDR, foi desenvolvido na Fundação Florestal entre todos os setores para que o processo de criação do edital seja feito de uma forma mais ágil. O TDR, possui dados como CNPJ da instituição, nome fantasia, dados do Presidente como RG, CPF, que são dados padrão para a minuta.

\section{MÉTODOS}

O software será desenvolvido na linguagem JAVA utilizando o software NetBens, por ser open-source e bem intuitivo para desenvolvimento, será utilizado também um banco de dados MySQL para armazenamento dos editais para que se houver outros editais parecidos ou até mesmo para renovar utilizar o mesmo. Utilizaremos uma minuta como modelo base para e especificamente Pregão Eletrônico que é disponibilizado no site da BEC - Bolsa Eletrônica de Compras e reunindo vários setores na Fundação Florestal desenvolvemos um modelo padrão para termo de referência que será usado como pré edital no gerador. Realizamos uma pesquisa de campo durante o mês de outubro para saber o tempo de criação do edital até sua publicação o setor de licitações demora em média 35 dias para completar o processo até sua publicação. Com os dados que colhemos, conseguimos desenvolver um modelo de TRD (Termo de Referência) no qual o solicitante preenche todas as informações padrão e quando é enviado para o setor de licitações utilizando alguns macros do MS Office, ele busca informações padrões do TDR e exporta direto na minuta do edital. O macro é um comando de instruções que agrupa informações do Termo de Referência diretamente na minuta. Com isso reduzimos em o processo de criação das duas primeiras etapas, no gerador a ideia é que todos os setores que o edital irá passar, eles soubessem antes de receber demanda e que dessa forma poderiam adiantar seus processos. 


\begin{tabular}{|l|l|l|}
\hline \multicolumn{3}{|c|}{ Editais Publicados } \\
\hline Mês & FF & BID \\
\hline jan/18 & 24 & 10 \\
\hline fev/18 & 10 & 0 \\
\hline mar/18 & 12 & 0 \\
\hline abr/18 & 14 & 0 \\
\hline mai/18 & 15 & 3 \\
\hline jun/18 & 9 & 2 \\
\hline jul/18 & 7 & 0 \\
\hline ago/18 & 6 & 8 \\
\hline set/18 & 10 & 3 \\
\hline out/18 & 5 & 1 \\
\hline Total & 112 & 27 \\
\hline
\end{tabular}

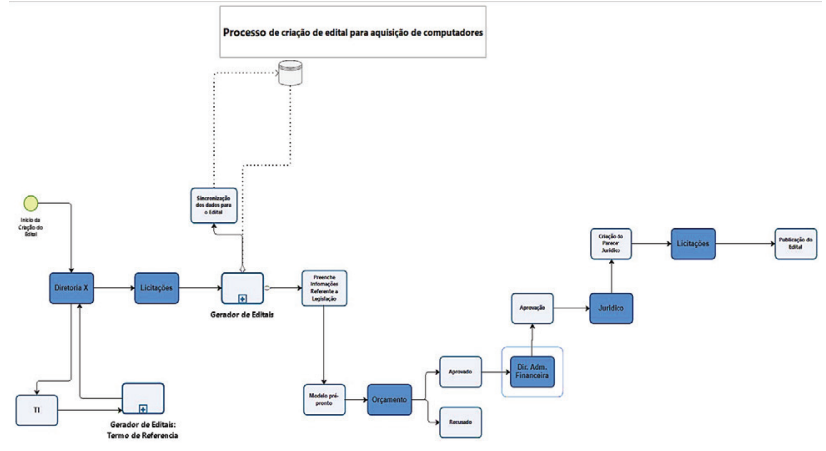

Figura 1 - BPM - Criação de Edital com o Gerador para aquisição de computadores

Como desenvolvemos um modelo de TDR padrão na instituição, antes de chegar no setor de licitações o gerador faz uma associação dos dados para a minuta de edital, assim quando o usuário do setor

Tabela 1 - Editais Publicados da Fundação Florestal e BID

Acima temos quantos editais no ano de 2018 foram gerados e publicados, como a fundação tem uma parceria com o BID (Banco Interamericano de Desenvolvimento), coletamos os dados deles também. No mês de outubro fizemos um acompanhamento da criação de um edital para aquisição de novas estações de trabalho na sede da Fundação Florestal, coletamos dados para a criação e como demonstrativo do gerador, utilizamos macros do MS Office para saber o quanto de tempo seria reduzido na criação conforme nos dados abaixo.

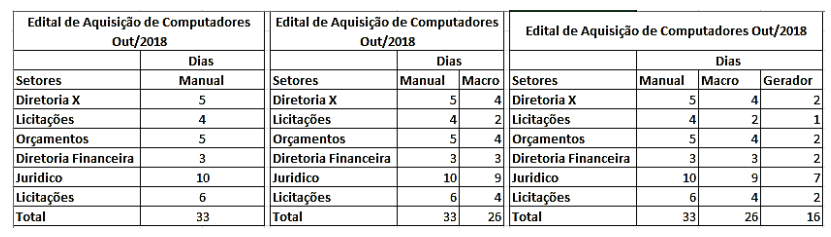

Tabela 2 - Tempo para criação de um edital

Desenvolvemos uma maneira automatizada no MS Office utilizando macros para associar dados do TDR para a minuta, como os dados sempre se repetem vimos um padrão entre o TRD e a Minuta, dessa forma usando a lógica de como o gerador irá funcionar conseguimos reduzir o tempo de criação do edital. Abaixo temos o modelo de criação de edital utilizado o gerador. de licitações abrir a minuta, todos os dados que ele precisaria preencher já vai estar no seu devido local preenchido.

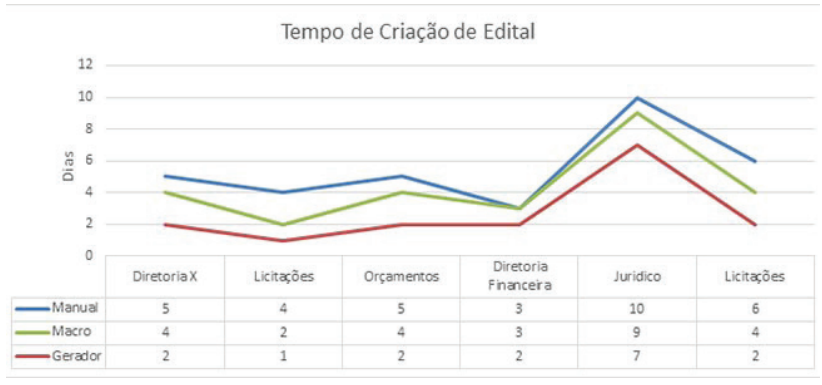

Quadro 1 - Comparativo de tempo de criação de edital

Com o gerador, conseguimos reduzir em $52 \%$ o processo de criação do edital até a sua publicação, com um banco de dados, usar o mesmo modelo adiantaria ainda mais o processo já que a maioria das vezes é o mesmo produto que está sendo licitado. $\mathrm{O}$ gerador ainda integra todos os setores para melhores desempenhos dos funcionários em questão.

\section{RESULTADOS E DISCUSSÃO}

As informações referidas durante janeiro até outubro de 2018 foram: Editais publicados entre a Fundação Florestal e o Banco Interamericano de Desenvolvimento - BID utilizando a rotina anterior totalizaram 139 licitações de modalidade pregão. A tabela 
tam de um auxílio para os processos, portanto os dados apresentados serão de grande importância para o desenvolvimento e a implantação do software na instituição. O software pode servir como auxilio para o processo de criação editais de forma mais ágil e com melhor qualidade, onde cada respectivo setor desenvolva sua parte sem precisar refazer o edital cada vez que é encontrado algum erro, dessa forma também diminuímos os custos com impressões e papeis. Para auxilio dos usuários, pretende-se criar um modelo de tutorial para dúvidas de utilização do gerador e de legislações no qual o usuário poderá pesquisar. 


\section{REFERÊNCIAS}

BOLSA ELETRÔNICA DE COMPRAS. Minutas especificas. Disponível em: <https://www.bec. sp.gov.br/becsp/Aspx/Minutas.aspx?chave $>$. Acesso em: 27 nov. 2018.

BOLSA ELETRÔNICA DE COMPRAS. Legislação. Disponível em: <https://www.bec.sp.gov.br/ becsp/Legislacao/UI_Selecao.aspx?chave>. Acesso em: 27 nov. 2018.

BPM CBOK. Guia para o gerenciamento de processos de negócios corpo comum de conhecimento ABPMP BPM CBOK versão 3.0. Disponível em: <https://c.ymcdn.com/sites/www.abpmp.org/ resource/resmgr/Docs/ABPMP CBOK Guide Portuquese.pdf>. Acesso em: 27 nov. 2018.

COORDENADORIA DO GOVERNO ELETRÔNICO. Apostila de MySQL. Disponível em: < $\underline{\text { http:// }}$ www.telecentros.sp.gov.br/saber/apostilas/antigas/ apostila_sql.pdf>. Acesso em: 27 nov. 2018.

FRANCO. Itamar. Lei № $\mathbf{8 . 6 6 6}$, de 21 de junho de 1993. Disponível em: <http://www.planalto.gov.br/ ccivil 03/Leis/L8666cons.htm>. Acesso em: 25 set. 2018.

FUNDAÇÃO FLORESTAL. Edital e licitação. Disponível em: < http://fflorestal.sp.gov.br/sites/edital-licitacao/>. Acesso em: 25 set. 2018.
FURTADO. L. R. Curso de licitações e contratos administrativos. Disponível em: < $\underline{\text { http:// }}$ www.stf.jus.br/arquivo/biblioteca/NovasAquisicoes/2011-07/901930/sumario.pdf>. Acesso em: 12 set. 2018.

GOVERNO. Órgãos e entidades. Disponível em:<http://www.saopaulo.sp.gov.br/orgaos-e-entidades>. Acessado em: 25 set. 2018.

MEIRELLES, Hely Lopes. Direito Administrativo Brasileiro. Disponível em: https://forumdeconcursos.com/wp-content/uploads/wpforo/ attachments/34777/1856-Hely-Lopes-Meirelles-Direito-Administrativo-Brasileiro-42-Ed-2016.pdf. Acesso em: 27 nov. 2018.

MICROSOFT. Criar ou executar uma macro. Disponível em: <https://support.office. com/pt-br/article/criar-ou-executar-uma-macro-c6b99036-905c-49a6-818a-dfb98b7c3c9c>. Acesso em: 27 nov. 2018.

NORMAS LEGAIS. Pregão eletrônico - Procedimentos. Disponível em: <http://www.normaslegais.com.br/guia/clientes/pregao-eletronico-procedimentos.htm>. Acesso em: 27 nov. 2018.

PERRY, Steven. Fundamentos da Linguagem Java. Disponível em: <https://www.ibm.com/developerworks/br/java/tutorials/j-introtojava1/index.html>. Acessado em: 27 nov. 2018. 